\title{
O SISTEMA PRODUTIVO DA INDÚSTRIA DO CINEMA BRASILEIRO E SUA DISPERSÃO CONCENTRADA
}

THE PRODUCTION SYSTEM OF THE BRAZILIAN FILM INDUSTRY AND ITS CONCENTRATED DISPERSION

\section{João Luiz de Figueiredo}

Doutor em Geografia, professor do Mestrado Profissional

em Gestão da Economia Criativa da ESPM-Rio.

E-mail: joao.silva@espm.br. 


\section{RESUMO}

O artigo trata da evolução da dinâmica produtiva da indústria do cinema brasileiro no período de 1995 a 2017, visando a evidenciar o fortalecimento da produção nacional e a emergência de novos centros de produção no país a partir da sua análise como um sistema produtivo. 0 argumento central reconhece a desverticalização do sistema produtivo da indústria do cinema e enfatiza a interdependência entre a produção de filmes hegemônicos e independentes, revelando a importância da escala comercial e da diversidade produtiva para a sustentabilidade do sistema produtivo e dos centros de produção emergentes. Através dessa perspectiva, trabalhamos com dados secundários disponibilizados pela ANCINE e pelo IBGE, de forma que verificamos o crescimento da produção no Brasil, o aumento da quantidade de empresas e de trabalhadores atuantes na indústria do cinema e a emergência de novos centros de produção, além do eixo Rio-São Paulo. Todavia, os novos centros ainda possuem o desafio de desenvolver a capacidade de realizar projetos possíveis de serem classificados como hegemônicos ou tenderão a perder profissionais para os centros do Rio e de São Paulo.

Palavras-chave: Indústria do cinema brasileiro. Sistema produtivo. Dispersão concentrada da produção.

\section{ABSTRACT}

The article deals with the evolution of the productive dynamics of the Brazilian film industry from 1995 to 2017, aiming to show the strengthening of national production and the emergence of new production centers in the country, through its analysis as a productive system. The central argument recognizes the deverticalization of the productive system of the film industry and emphasizes the interdependence between the production of hegemonic and independent films, revealing the importance of commercial scale and diversity for the sustainability of the productive system and of the emerging production centers. From this perspective, we work with secondary data offered by ANCINE and IBGE, so that we can see the growth of production in Brazil, the increase in the number of companies and workers in the film industry and the emergence of new production centers besides Rio de Janeiro and São Paulo. However, the new production centers still face the challenge of developing the capacity to carry out projects that could be classified as hegemonic or tend to lose professionals to Rio and São Paulo.

Keywords: Brazilian film industry. Production system. Concentrated dispersion of production. 


\section{INTRODUÇÃo}

O presente artigo trata da evolução da dinâmica produtiva da indústria do cinema brasileiro no período de 1995 a 2017. O principal objetivo é evidenciar o fortalecimento da produção nacional e a emergência de novos centros de produção no país a partir da sua análise como um sistema produtivo.

Ao analisar a indústria do cinema como um sistema produtivo, o argumento central do artigo enfatiza a interdependência entre as empresas e os trabalhadores que compõem a indústria e também entre produção de filmes que são orientados para o sucesso comercial com aqueles que possuem orientação mais autoral, revelando a importância da escala comercial e da diversidade produtiva para a sustentabilidade do sistema produtivo. Ao longo do artigo classificaremos esses filmes como integrantes de dois subsistemas que são complementares, o subsistema hegemônico e o subsistema independente. Portanto, a interpretação da dinâmica produtiva da indústria do cinema pelo viés da sua organização como um sistema produtivo nos leva a analisar o conjunto produtivo em vez de empresas ou projetos isoladamente.

O recorte temporal do trabalho se estende de 1995, ano identificado como o marco inicial da fase conhecida como Retomada na indústria do cinema brasileiro, até 2017, que no momento de encerramento deste texto era o último ano com dados consolidados e disponibilizados pela Agência Nacional do Cinema (ANCINE). Isso significa que a análise do sistema produtivo carrega consigo sempre limitações temporais, de maneira que o seu dinamismo exige permanente atualização da pesquisa, todavia, os dados disponíveis no momento são extremamente atuais e permitem a caracterização do sistema produtivo da indústria do cinema brasileiro e a evidenciação do seu fortalecimento e da emergência de novos centros de produção.

Em nossa metodologia de investigação, levantamos dados secundários, disponibilizados pela ANCINE, que revelam dois resultados: o crescimento da produção no Brasil, especialmente daquela que identificaremos posteriormente no trabalho como independente, e a emergência de novos centros de produção, além do eixo Rio-São Paulo.

Para analisar os dados e evitar a simples descrição, os dois resultados acima foram problematizados pela ótica econômica-territorial dos sistemas produtivos desverticalizados, que se configuram, no capitalismo deste início de Século XXI, em aglomerações de tamanhos variados de empresas e de trabalhadores interdependentes (Scott, 2000). Nessa perspectiva, para contribuir com a problematização acerca da emergência de novos centros de produção da indústria cinematográfica nacional, tratamos dados secundários extraídos da base de dados do Instituto Brasileiro de Geografia e Estatística (IBGE) conhecida como Sistema IBGE de Recuperação Automática (SIDRA), os quais revelam o aumento da quantidade de empresas e de trabalhadores envolvidos com as atividades cinematográficas, produção de vídeos e de programas de televisão na imensa maioria dos estados do Brasil. 
Dessa forma, é importante sublinhar que o nosso ol har não se direciona para as empresas específicas ou para determinados filmes, apesar de algumas empresas e filmes serem mencionados ao longo do texto, e tampouco nos interessa o relevante debate estético e artístico associado à indústria do cinema e a outras indústrias culturais e criativas, de modo que ratificamos a lente econômica que lançamos sobre a indústria do cinema neste artigo.

$\mathrm{O}$ artigo está estruturado em duas seções, além da introdução e das considerações finais. Na primeira, intitulada "Evidências do fortalecimento da produção cinematográfica nacional e da emergência de novos centros de produção", apresentamos os resultados do levantamento de dados secundários sobre a produção cinematográfica no Brasil ao longo do período de 1995 a 2017; na segunda seção, intitulada "A organização do sistema produtivo da indústria do cinema brasileiro" apresentamos uma tipologia que diferencia os filmes produzidos entre hegemônicos e independentes, de maneira a viabilizar uma melhor compreensão sobre a interdependência entre os agentes produtivos do sistema, assim como para qualificar o processo de dispersão da dinâmica produtiva para outros centros, além do eixo Rio-São Paulo.

\section{EVIDÊNCIAS DO FORTALECIMENTO DA PRODUÇÃO CINEMATOGRÁFICA NACIONAL E DA EMERGÊNCIA DE NOVOS CENTROS DE PRODUÇÃO}

A indústria do cinema, assim como outras atividades culturais e criativas, tende a se concentrar espacialmente nas metrópoles que ocupam os maiores níveis na hierarquia urbana, seja a análise em escala mundial ou nacional. Dessa forma, são em metrópoles como Los Angeles, Nova York, Londres, Paris, Tóquio, Cidade do México, Buenos Aires e outras de semelhante hierarquia que verificamos a maior parte da produção cinematográfica mundial, ao passo que, ao tratarmos da concentração da produção cinematográfica brasileira, a primazia cabe às cidades do Rio de Janeiro e de São Paulo.

Em uma análise geral, a tendência de concentração espacial dessa produção decorre da profunda desverticalização do sistema produtivo da indústria do cinema, explicada detalhadamente por Storper e Christopherson (1987) que analisaram tal processo em Hollywood, e da consequente interdependência entreasfirmas envolvidas no processo produtivo, que segundo Scott(2000; 2005) favorece a materialização espacial de aglomerações produtivas de firmas e de trabalhadores, cuja proximidade permite alcançar as vantagens do mercado de trabalho concentrado e a inserção nos fluxos de informação e de inovação existentes em lugares onde diferentes produtores complementares se congregam.

Em suma, a indústria do cinema se materializa no espaço urbano das metrópoles globais ou nacionais sob a forma de aglomerações produtivas, que consistem em uma densa concentração de unidades produtivas em um local e pela existência de uma forte interdependência funcional e de externalidades que 


\section{Gestãoe \\ Desenvolvimento}

ligam essas unidades em um conjunto. A origem das externalidades reside na rede interfirmas, no mercado local de trabalho e nos efeitos de aprendizado que são comumente encontrados nas aglomerações, sendo potencializadas pela infra-estrutura física e institucional existente. Dessa forma, a aglomeração tende a gerar fontes de benefícios na forma de efeitos de retorno positivo que suportam as vantagens competitivas de cada unidade produtiva, as quais podem ser compreendidas na perspectiva territorial, ou seja, vantagens territorialmente construídas.

Dessa forma, podemos perceber que mesmo em um Mundo globalizado marcado por uma profunda fluidez de pessoas, mercadorias e informações, a atividade cinematográfica e outras da economia criativa tendem a se concentrar espacialmente, pois a competitividade e a própria capacidade de realização do projeto dependem crucialmente da localização. Como apontado anteriormente, essa localização tende a ser nas cidades que ocupam o topo da hierarquia urbana global e nacional, pois, como demonstra Veltz (1999), a heterogeneidade metropolitana propicia uma diversidade de recursos e acesso a uma densa rede de informações que são elementos centrais da competitividade de atividades que demandam velocidade na tomada de decisões e possuem incerteza quanto aos resultados finais; claramente o caso da indústria cinematográfica. 
Entretanto se, por um lado, é correto afirmar a tendência de concentração da atividade cinematográfica em um seleto grupo de cidades, por outro lado, verificamos o aumento da quantidade de cidades que reúnem tais características, de modo que podemos afirmar existir uma dispersão concentrada da produção cinematográfica pelo Mundo, ou seja, a dispersão se manifesta de maneira extremamente seletiva em termos espaciais, conforme verifica-se nas palavras de Scott (2005):

Spatial clusters of producers in the modern cultural economy are unlikely to dissolve, at least for the foreseeable future. The extreme prediction of an overall dispersal of formerly agglomerated production activities to isolated locations scattered across the globe is certainly not anywhere close to realization.

(...) the modern cultural economy is evolving toward a locational pattern made up of multiple clusters of different sizes and market power rooted in a global mosaic of large metropolitan regions. No matter how limited or far-reaching this trend may turn out to be, it will almost certainly involve some incursions into Hollywood's market power and the growth of at least a small number of alternative sites of audiovisual production with global reach (SCOTT, 2005, p. 174). ${ }^{1}$

Diante desse debate, interessa-nos identificar, na dinâmica espacial da produção cinematográfica brasileira, se está em curso a formação de outros centros de produção além dos já consolidados historicamente do Rio de Janeiro e de São Paulo. Seria possivel notarmos também alguma tendência de dispersão concentrada da atividade produtiva cinematográfica no Brasil? Para responder a essa questão, devemos analisar os dados de produção do cinema brasileiro que são disponibilizados anualmente pela ANCINE.

Antes da apresentação dos dados, cabe esclarecermos os critérios adotados no tratamento das informações coletadas. Primeiramente, a análise é exclusiva sobre filmes de longa-metragem, documentário, ficção ou animação, que tenham sido exibidos pelo menos uma semana em alguma sala de cinema; em segundo lugar, a localidade da produção foi definida de acordo com a sede da produtora e, nos casos de projetos com produtoras de duas ou mais unidades da federação, optamos por categorizar

\footnotetext{
${ }_{1}^{1}$ Aglomerações espaciais de produtores na moderna economia cultural não são suscetíveis a se dissolverem, pelo menos em um futuro previsível. A previsão extremada de uma dispersão global das já formalizadas aglomerações produtivas em pontos locacionais isolados espalhados por todo o globo não está perto de se realizar.

(...) a economia cultural moderna está evoluindo para um padrão locacional constituído de múltiplas aglomerações com diferentes tamanhos e força mercantil enraizada em um mosaico global de grandes regiões metropolitanas. Não importa quão limitada ou de longo alcance seja esta tendência, ela certamente implicará em algumas incursões na força de mercado de Hollywood e no crescimento de pelo menos um pequeno número de sítios alternativos de produção audiovisual com alcance global. (Tradução do autor).
} 
a localização do projeto de acordo com a sede da produtora majoritária; também é importante informar que, embora reconheçamos a tendência da concentração da produção nas cidades, os dados selecionadas da ANCINE estabelecem a sede da produtora pelo estado, todavia, na maioria dos casos, a produtora está localizada na capital do estado e não atrapalha a análise que propomos; por fim, selecionamos o recorte temporal de 1995 a 2017, de modo a analisar a dinâmica produtiva desde o início da chamada Retomada, que "designa o processo de recuperação da produção cinematográfica no Brasil depois de uma de suas mais graves crises, no começo dos anos 90" (BUTCHER, 2005, p. 14).

Gráfico 1 - Evolução absoluta da produção cinematográfica brasileira por sede da produtora (1995-2017)

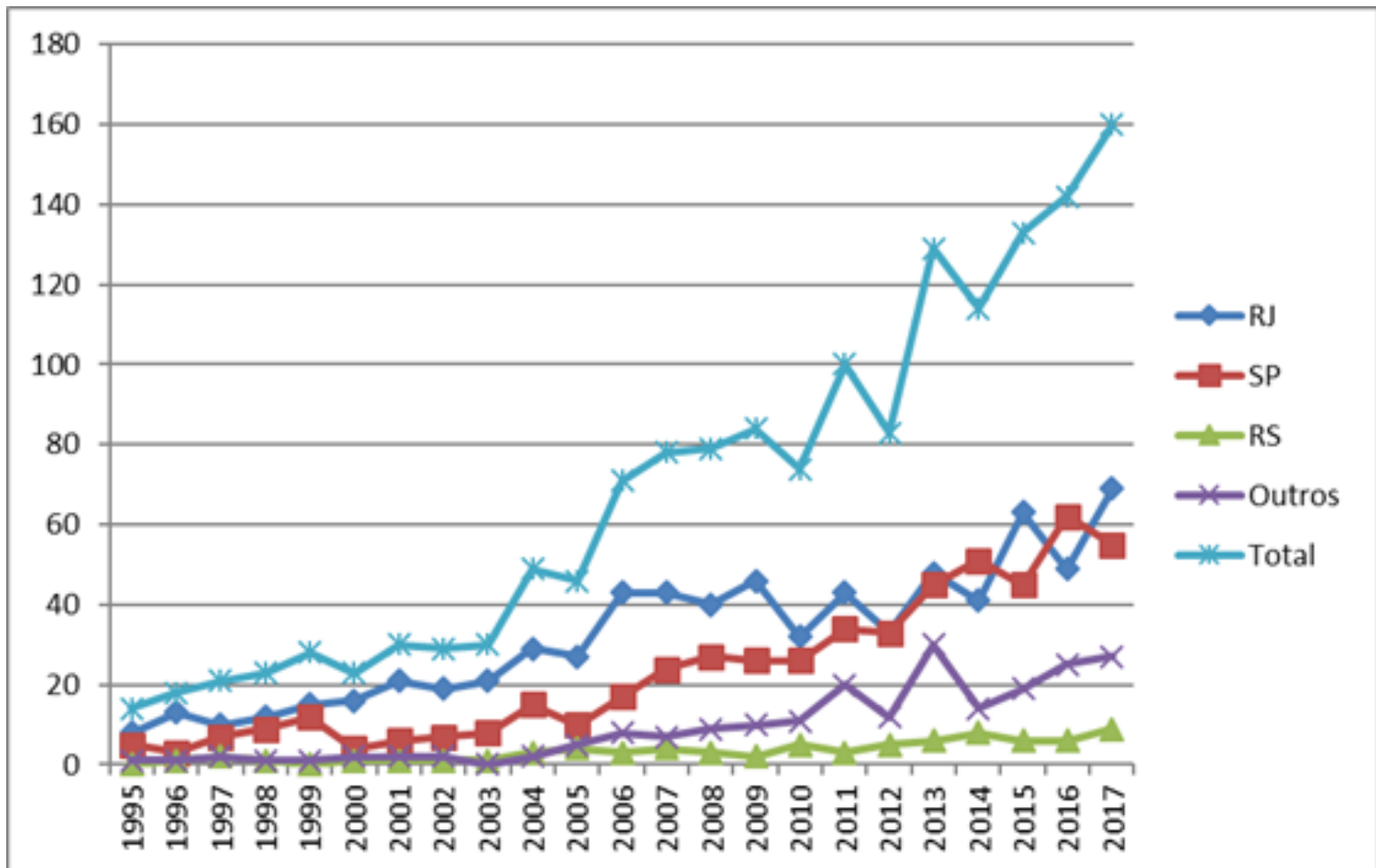

Fonte: Elaborado pelo autor com base em dados públicos disponibilizados pela ANCINE (2018) 
Gráfico 2 - Evolução da fatia da produção cinematográfica brasileira (\%) por sede da produtora (1995-2017)

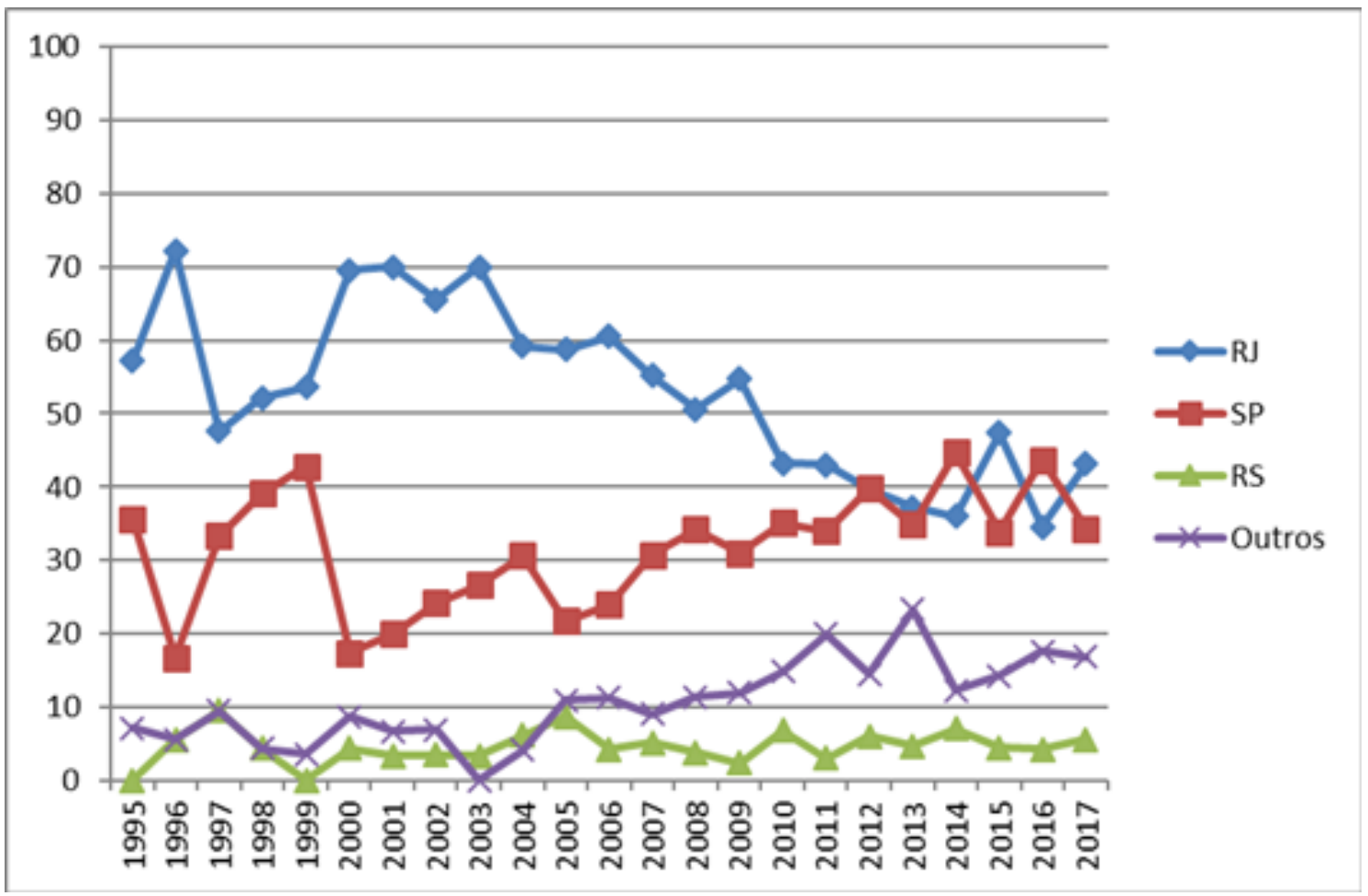

Fonte: Elaborado pelo autor com base em dados públicos disponibilizados pela ANCINE (2018) 


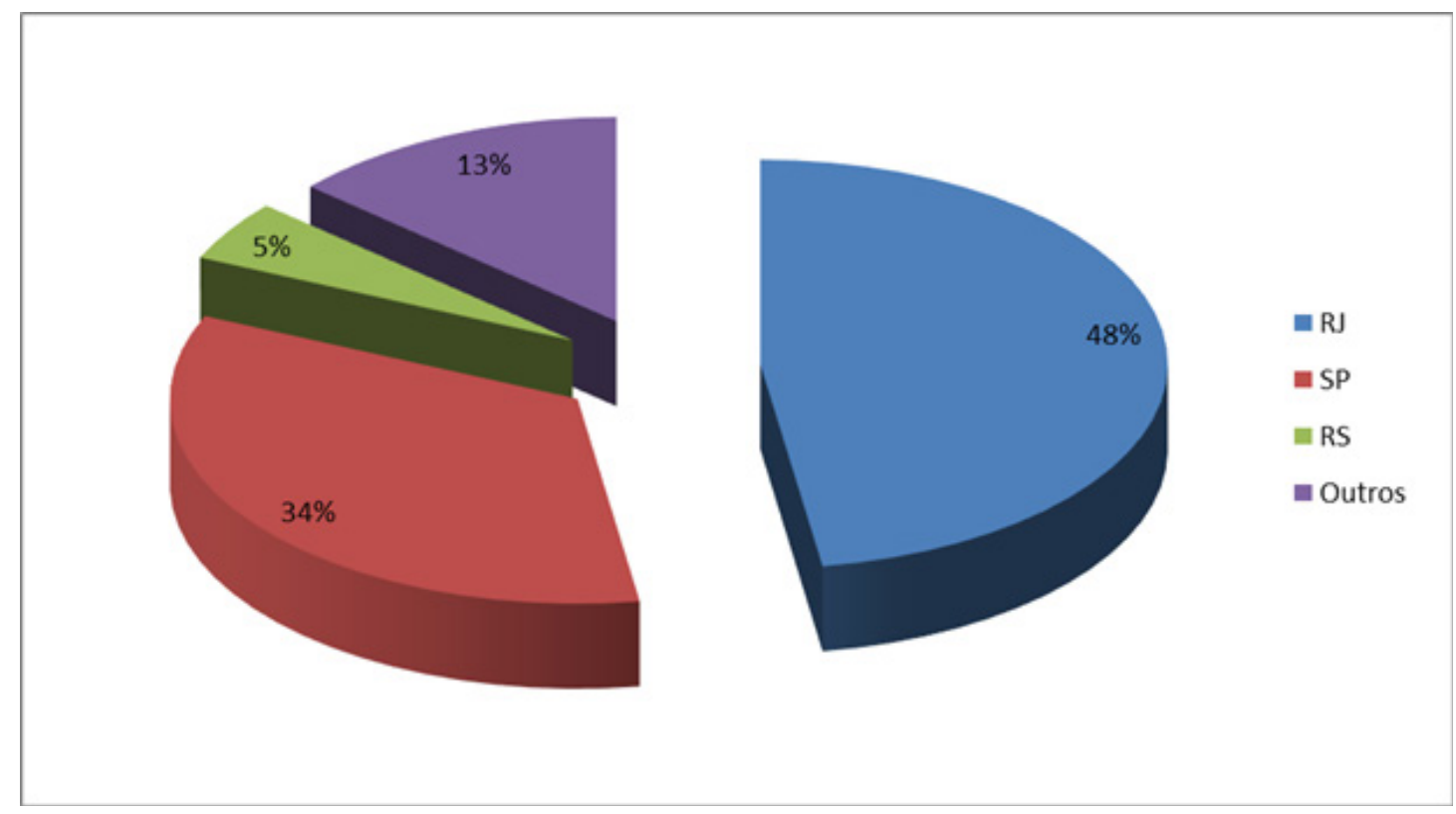

Fonte: Elaborado pelo autor com base em dados públicos disponibilizados pela ANCINE (2018)

Embora os gráficos já viabilizem a leitura das informações, consideramos importante destacar alguns pontos centrais para o objetivo do presente artigo. Primeiramente, é inegável a consolidação de uma dinâmica produtiva da indústria do cinema no país, pois o crescimento absoluto de 13 filmes lançados em 1995 para 160 em 2017 significa, em termos percentuais, um incremento de mais de 1.000\% da oferta de filmes nacionais de longa-metragem para o cinema; apenas Rio de Janeiro e São Paulo possuem uma produção perene para todo o período analisado, enquanto Rio Grande do Sul assume tal condição a partir do ano 2000, de modo que por esse motivo optamos por destacar essas unidades da federação e agregar as demais na categoria "outros", a qual apenas a partir de 2004 se tornou perene na oferta de filmes com um importante crescimento de 2 filmes lançados em 2004 para 27 em 2017; Rio de Janeiro e São Paulo são os centros mais importantes de produção, com destaque para o recente crescimento da produção em São Paulo; em termos agregados para todo o período, a produção cinematográfica fora do eixo Rio-SP equivale a 18\%, sendo 5\% no Rio Grande do Sul e 13\% nos demais estados.

Embora os dados confirmem a enorme concentração da dinâmica produtiva no eixo Rio-SP, notase a emergência de centros de produção fora desse eixo, de modo que torna-se importante abrir os dados que classificamos anteriormente como "outros". Dessa forma, no quadro 1 abaixo, demonstra-se a 
evolução da dinâmica produtiva fora do eixo Rio-SP, a partir de 2004, ano que marca o início da perenidade da produção nesses centros, para além do Rio Grande Sul, cuja perenidade se verifica desde 2000. Para efeitos de melhor comparação, optamos por também inserir no quadro as informações do Rio Grande do Sul e do eixo Rio-SP.

Quadro 1 - Evolução absoluta da produção cinematográfica brasileira por sede da produtora (2004-2017)

\begin{tabular}{|c|c|c|c|c|c|c|c|c|c|c|c|c|c|c|}
\hline UF & 2004 & 2005 & 2006 & 2007 & 2008 & 2009 & 2010 & 2011 & 2012 & 2013 & 2014 & 2015 & 2016 & 2017 \\
\hline Rio/SP & 44 & 37 & 60 & 67 & 67 & 72 & 58 & 77 & 66 & 93 & 92 & 108 & 111 & 124 \\
\hline RS & 3 & 4 & 3 & 4 & 3 & 2 & 5 & 3 & 5 & 6 & 8 & 6 & 6 & 9 \\
\hline MG & & 2 & 2 & 3 & 3 & & 4 & 3 & 4 & 1 & 3 & 2 & 4 & 2 \\
\hline PE & & 1 & & 1 & 1 & 1 & 2 & 5 & 1 & 8 & 3 & 4 & 6 & 7 \\
\hline DF & & 2 & 2 & & 1 & 2 & 1 & 3 & 1 & 5 & 3 & 4 & 3 & 1 \\
\hline PR & & & & 1 & 2 & 2 & 1 & 1 & 3 & 2 & 1 & 2 & 5 & 3 \\
\hline BA & 1 & & 1 & 1 & & 1 & & 4 & 2 & 4 & 2 & 2 & 1 & 5 \\
\hline CE & & & & 1 & 1 & 2 & 1 & 3 & 1 & 5 & & 1 & 1 & 5 \\
\hline SC & 1 & & 2 & & & 2 & 1 & 1 & & 1 & & 2 & 1 & \\
\hline ES & & & & & & & & & & 1 & 1 & & 1 & \\
\hline MT & & & 1 & & & & 1 & & & & & & 1 & \\
\hline MA & & & & & & & & & & 1 & & & 2 & \\
\hline PB & & & & & & & & & & & & 2 & & 1 \\
\hline AM & & & & & & & & & & 1 & & & & 1 \\
\hline GO & & & & & & & & & & 1 & & & & 1 \\
\hline SE & & & & & & & & & & & 1 & & & \\
\hline PA & & & & & 1 & & & & & & & & & \\
\hline MS & & & & & & & & & & & & & & 1 \\
\hline Total & 49 & 46 & 71 & 78 & 79 & 84 & 74 & 100 & 83 & 129 & 114 & 133 & 142 & 160 \\
\hline
\end{tabular}

Fonte: Elaborado pelo autor com base em dados públicos disponibilizados pela ANCINE (2018)

Pelos dados do quadro, podemos verificar a intermitência que caracteriza a dinâmica produtiva dos centros de produção fora do eixo Rio-SP, exceção feita ao Rio Grande do Sul, como explicado anteriormente, 
porém, devemos sublinhar a possibilidade de consolidação de uma dinâmica produtiva em Minas Gerais, Pernambuco, Distrito Federal e Paraná, os quais apresentam perenidade na produção desde 2008, e Bahia, que apresenta perenidade desde 2011. Os estados do Ceará e de Santa Catarina também possuem uma dinâmica produtiva em desenvolvimento, mas com falta de perenidade já que ficaram pelo menos um ano sem lançar filmes no período em análise.

Acreditamos que a tendência para os próximos anos é de aumento da produção nesses novos centros, uma vez que os principais editais nacionais de fomento à produção cinematográfica passaram a adotar parâmetros de indução regional, assim como verificamos também a criação de escolas de cinema e a ampliação de políticas de incentivo estaduais e municipais nesses novos centros. Todavia se, por um lado, verifica-se a dispersão da produção, por outro lado, reconhecemos que isso acontece de maneira concentrada, reforçando a tese de uma dispersão concentrada da produção. Assim, se considerarmos o período inteiro selecionado de 2004 a 2017, cujos dados estão no quadro 1, o Rio Grande do Sul permanece como um centro de produção emergente, mas agora acompanhado de outros, como Minas Gerais, Pernambuco, Distrito Federal e Paraná.

Os três gráficos e o quadro anteriores demonstraram a ampliação da capacidade produtiva da indústria do cinema brasileiro, entretanto, eles não trataram da demanda por tais filmes, de modo que os gráficos 4, 5 e 6, abaixo, revelam a evolução do público dos filmes brasileiros, de acordo com o tratamento que nos interessa no artigo. Analisar a demanda dos filmes é de fundamental importância, pois qualquer atividade econômica depende de público e de renda para obter sustentabilidade em sua trajetória.

Se pela ótica da oferta apresentada nos gráficos 1, 2 e 3 podemos visualizar uma tendência, ainda que inicial, de desconcentração da produção cinematográfica brasileira, pela ótica da demanda tal resultado não ocorre, uma vez que se verifica ainda a extrema concentração do público do cinema brasileiro nos filmes produzidos pelas produtoras do Rio de Janeiro e em seguida pelas produtoras de São Paulo.

Vale destacar como tendência recente a conquista de mercado das produções oriundas de São Paulo, de modo que o ano de 2016 marca a primeira vez que as produções realizadas em São Paulo assumem a liderança de mercado, fato extremamente relacionado à exibição da adaptação de uma novela da Rede Record de Televisão para o cinema, o que será problematizado mais à frente no artigo. No acumulado do período, chama a atenção o fato de $74 \%$ do mercado de filmes brasileiros ter sido conquistado pelas produções do Rio de Janeiro, enquanto as produções de São Paulo conquistaram 24\% e apenas 2\% foi conquistado pelos projetos executados fora do eixo Rio-SP. Importante, portanto, sublinhar através da comparação dos gráficos 3 e 6 que, apesar de 18\% dos filmes serem de fora do eixo Rio-SP, a fatia de mercado deles é de apenas $2 \%$. 
Gráfico 4 - Evolução absoluta do público do cinema brasileiro por sede da produtora (1995-2017)

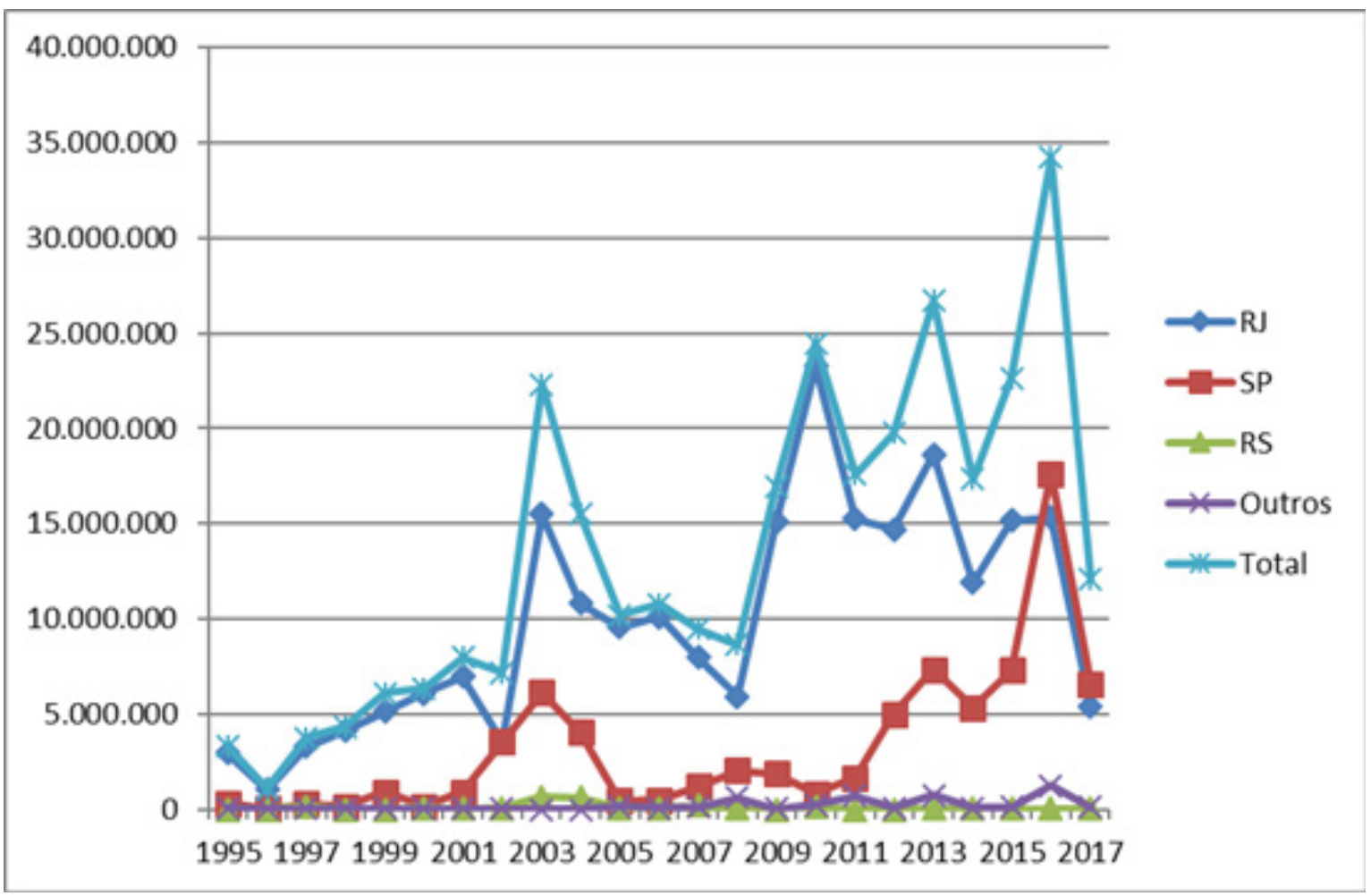

Fonte: Elaborado pelo autor com base em dados públicos disponibilizados pela ANCINE (2018) 
Gráfico 5 - Evolução da fatia de mercado do cinema brasileiro (\%) por sede da produtora (1995-2017), classificados por público

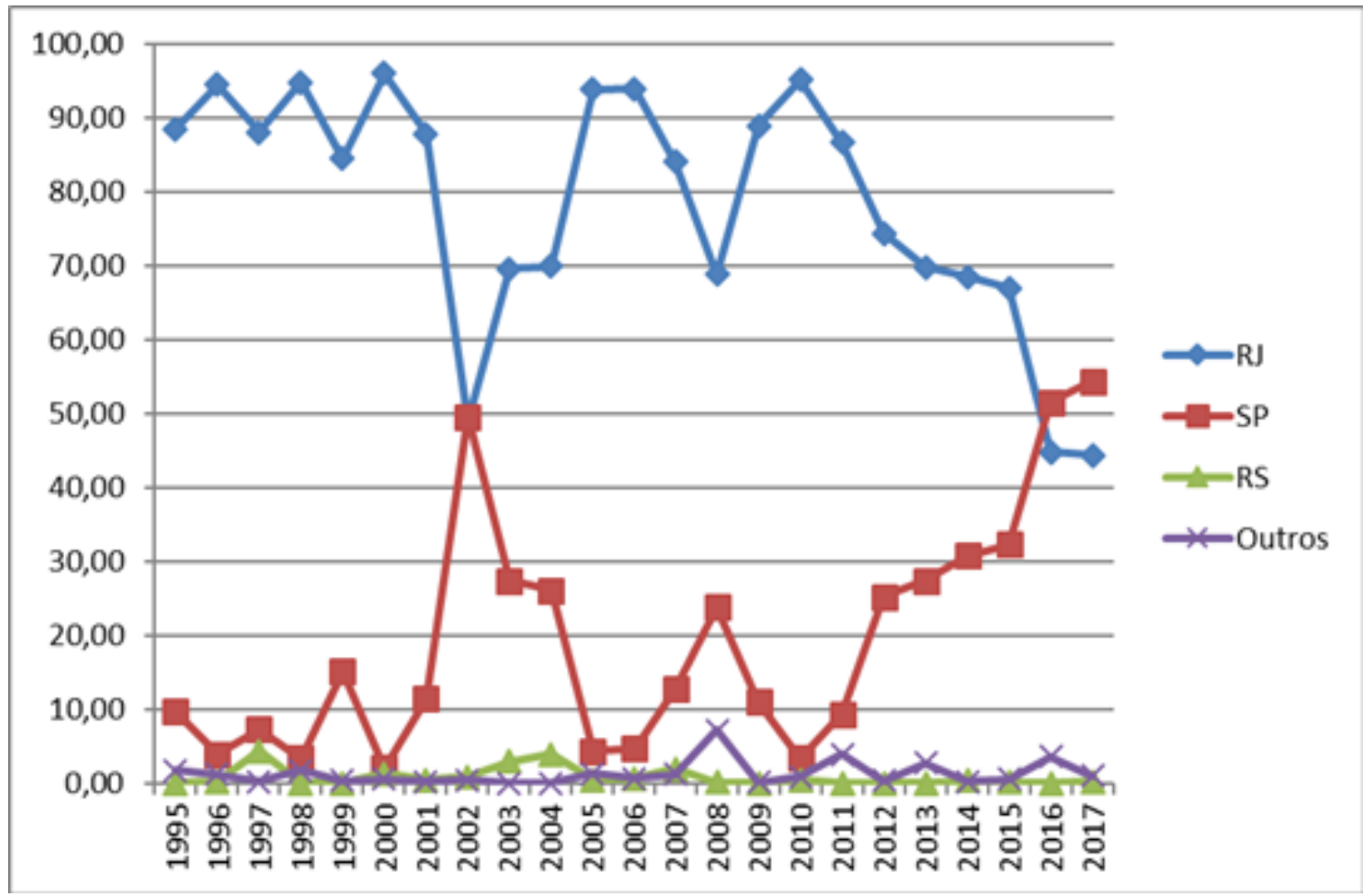

Fonte: Elaborado pelo autor com base em dados públicos disponibilizados pela ANCINE (2018) 


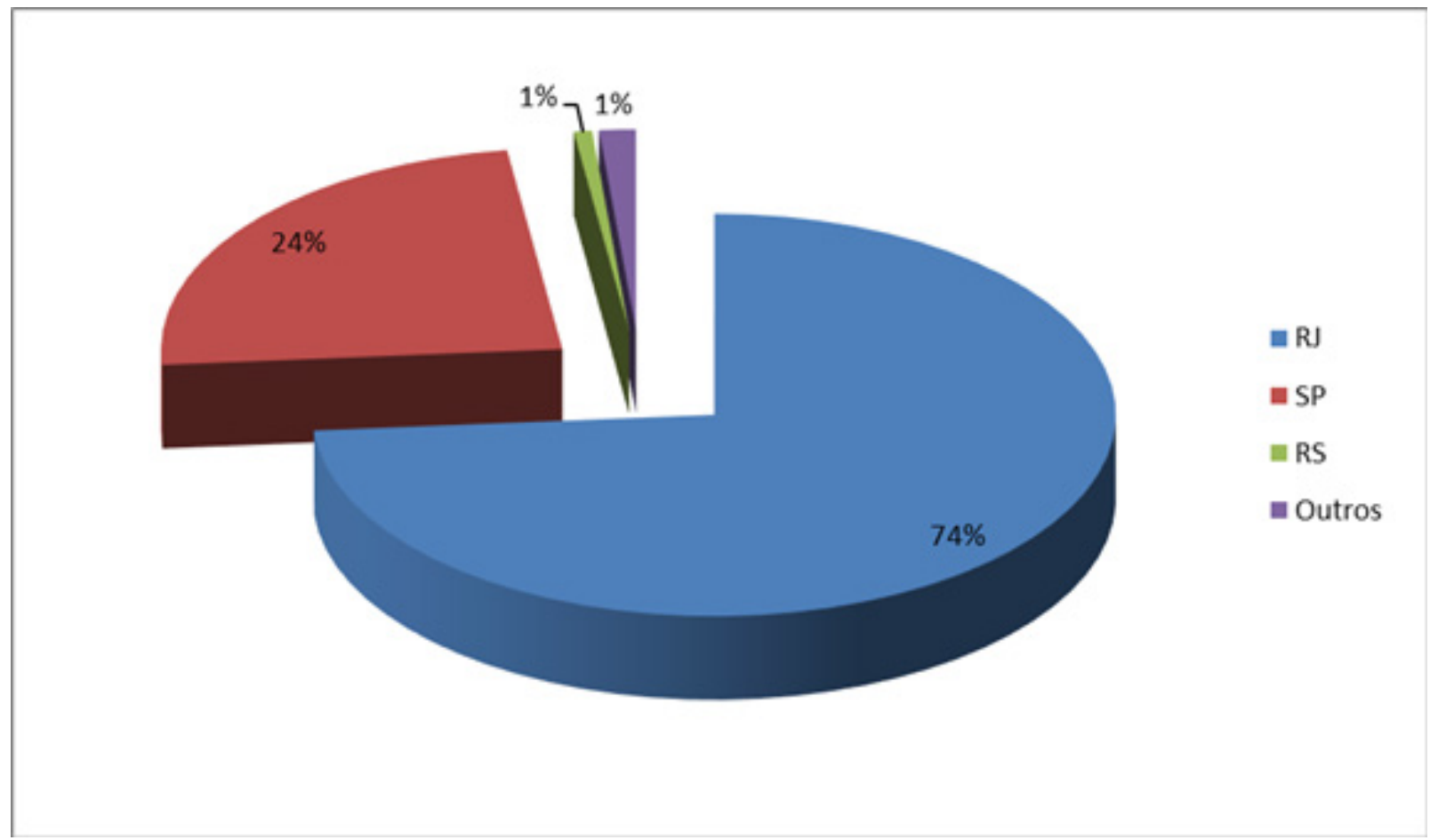

Fonte: Elaborado pelo autor com base em dados públicos disponibilizados pela ANCINE (2018)

Se, por um lado, os dados podem reforçar argumentos defensores da redução da produção cinematográfica brasileira e da concentração dos recursos produtivos no eixo Rio-São Paulo em função dos frágeis resultados de mercado da maioria das produções nacionais, especialmente das localizadas nos centros de produção emergentes, por outro lado, devemos analisar melhor a dinâmica de consolidação produtiva de uma indústria do cinema sustentável, ou seja, que tenha viabilidade financeira no curto prazo, mas também vitalidade e capacidade de renovação no longo prazo.

Não é objetivo deste artigo avaliar esteticamente a qualidade dos filmes brasileiros e dessa forma o nosso argumento a respeito da dinâmica produtiva é de que existem muitas relações desconhecidas entre os filmes que são sucesso de bilheteria e os que não obtém tal performance. Assim, mesmo que pareça incoerente do ponto de vista comercial, é necessário que tenhamos excesso de oferta e, principalmente, diversidade para que possamos consolidar uma indústria do cinema competitiva. Aliás, vale mencionar o atual paradoxo das indústrias culturais, que consiste em concentração do mercado em poucos títulos 
apesar do aumento expressivo da produção, como bem explica Alberse (2014), através da estratégia dos blockbusters, e como bem evidenciam Lipovetsky e Serroy (2015), ao apresentarem números da indústria do cinema da França e dos Estados Unidos:

\begin{abstract}
As indústrias culturais lançam cada vez mais produtos, mas somente uma pequena proporção deles alcança sucesso e dá lucro: em 2005, apenas quatro filmes franceses venderam mais de 2 milhões de ingressos no país. E dos 1296 filmes franceses exibidos nas salas entre 1991 e 2001, 701 venderam menos de 25 mil ingressos. Nesse sistema, um produto que tem êxito absorve as perdas da maioria (...)

No cinema, a média dos resultados registrados pelas majors hollywoodianas e, mais comum, pelos estúdios com uma produção importante revela que somente um terço dos filmes dá dinheiro, um terço garante seu equilíbrio e um terço é deficitário (...) Nesse setor profundamente marcado pela incerteza e pela imprevisibilidade do sucesso, dada a impossibilidade de prever o que conquistará o público, a lógica econômica leva a multiplicar os produtos, a produzir sempre mais para multiplicar as chances de êxito, o que aumenta ainda mais o poderio das majors, as únicas que dispõem de meios próprios para assumir essa estratégia (LIPOVETSKY; SERROY, 2015, p. 102-103).
\end{abstract}

Se, por um lado, verifica-se a concentração do mercado em um reduzido número de títulos, por outro lado, a sustentabilidade da indústria em termos de inovação e de revelação de novos talentos decorre da extensa lista de filmes com reduzido sucesso comercial, nos quais desenvolvem-se a aprendizagem dos novos talentos criativos e os processos de experimentação e inovação das novas estéticas, temas e linguagens.

Portanto, para que possamos atingir o objetivo do artigo, que consiste em evidenciar o fortalecimento da produção nacional e a emergência de novos centros de produção no país a partir da sua análise como um sistema produtivo, resta-nos avançar para a próxima seção do artigo, na qual analisaremos a indústria do cinema do Brasil como um sistema produtivo. Assim poderemos debater a importância da convivência entre filmes com performance comercial com outros que não possuem tal desempenho, bem como a complementaridade entre os centros de produção emergentes e os já consolidados como Rio e São Paulo.

\title{
3 A ORGANIZAÇÃO DO SISTEMA PRODUTIVO DA INDÚSTRIA DO CINEMA BRASILEIRO
}

Os dados da seção anterior evidenciam o fortalecimento da dinâmica produtiva da indústria cinematográfica brasileira e a emergência de novos centros de produção, especialmente nos estados de Rio Grande do Sul, Minas Gerais, Pernambuco, Distrito Federal e Paraná, todavia, eles são insuficientes em revelar a relação produtiva existente entre os agentes da indústria do cinema brasileiro. Por esse motivo, 
cabe-nos perguntar nesse momento: como se organiza o sistema produtivo da indústria do cinema brasileiro? Por que o crescimento da produção é importante para a sustentabilidade e para a diversidade do sistema? Como podemos compreender a emergência de novos centros de produção como resultado da expansão do sistema produtivo da indústria do cinema brasileiro?

A partir da década de 1960, em função do encerramento das operações dos grandes estúdios cinematográficos no Brasil (Atlântida e Vera Cruz foram os mais expoentes), o sistema produtivo da indústria do cinema brasileiro iniciou o seu processo de desverticalização, que se intensificou com a retomada da produção cinematográfica em meados da década de 1990, e se configura atualmente em uma rede de interações entre as diversas empresas que o compõem. Nos sistemas produtivos desverticalizados, como é o caso da indústria cinematográfica, os elos produtivos não estão dentro das empresas, mas nos territórios, de maneira que o sistema produtivo se constitui pelo conjunto das transações existentes entre empresas pequenas, especializadas e interdependentes.

Quanto maior o número de empresas, maior a intensidade das interações do sistema, sendo essa uma característica fundamental para a consolidação dos centros de produção, ou seja, não basta ter algumas empresas produzindo, é necessária a existência de interações produtivas entre as diversas empresas de forma a criar um fluxo de aprendizagem que progressivamente se territorializa como uma competência produtiva do local. Essa dinâmica de territorialização de uma competência produtiva ocorre de forma lenta ao longo do tempo, como demonstram os estudos dos pesquisadores, como Storper (1997; 2013), Scott (2000; 2005) e Diniz e Lemos (2005), que relacionam a performance econômica dos locais com as competências territoriais historicamente construídas.

Na esteira desse processo, espera-se que ocorra a proliferação do número de empresas relacionadas ao sistema produtivo. No quadro 2, sintetizamos informações disponibilizadas na base de dados SIDRA do IBGE, que revelam a evolução do número de empresas e do pessoal ocupado nas atividades cinematográficas, produção de vídeos e de programas de televisão. Como se pode notar, na comparação entre os anos de 2010 e 2015, há aumento do número de empresas e do pessoal ocupado em muitas Unidades da Federação, fenômeno que se torna ainda mais significativo se considerarmos a profunda crise econômica enfrentada pelo país em 2015. Além disso, é interessante notar que, ao analisarmos a proporção das empresas das atividades selecionadas sobre o total das empresas e a proporção do pessoal ocupado nessas atividades sobre o total do pessoal ocupado, a média nacional é superada apenas no Rio de Janeiro e em São Paulo, de modo que podemos reconhecer a emergência de novos centros de produção, mas também ratificar a consolidação do eixo Rio-São Paulo como o mais dinâmico do país. 
Quadro 2 - Número de empresas e de pessoas ocupadas em atividades cinematográficas, produção de vídeos e de programas de televisão em 31/12 de 2010 e de 2015

\begin{tabular}{|c|c|c|c|c|c|c|c|c|c|c|}
\hline \multirow{3}{*}{$\begin{array}{c}\text { Brasil e } \\
\text { estados }\end{array}$} & \multicolumn{5}{|c|}{ Número de empresas } & \multicolumn{5}{|c|}{ Número de pessoas ocupadas } \\
\hline & \multicolumn{2}{|c|}{ Quantidade } & \multirow{2}{*}{$\begin{array}{c}\text { Variaçà̀o } \\
(\%)\end{array}$} & \multicolumn{2}{|c|}{$(\%)$ no total geral } & \multicolumn{2}{|c|}{ Quantidade } & \multirow{2}{*}{$\begin{array}{c}\text { Variaçào } \\
(\%)\end{array}$} & \multicolumn{2}{|c|}{$(\%)$ no total ger al } \\
\hline & 2010 & 2015 & & 2010 & 2015 & 2010 & 2015 & & 2010 & 2015 \\
\hline Brasil & 10581 & 13186 & $24,62 \%$ & 0,21 & 0,26 & 35615 & 47001 & $31,97 \%$ & 0,07 & 0,09 \\
\hline RO & 31 & 32 & $3,23 \%$ & 0,1 & 0,1 & 142 & 194 & $36,62 \%$ & 0,04 & 0,06 \\
\hline $\mathrm{AC}$ & 14 & 11 & $-21,43 \%$ & 0,15 & 0,13 & $\mathrm{X}$ & $\mathrm{x}$ & - & $\mathrm{X}$ & $\mathrm{x}$ \\
\hline AM & 37 & 35 & $-5,41 \%$ & 0,11 & 0,11 & 255 & 175 & $-31,37 \%$ & 0,04 & 0,03 \\
\hline RR & 8 & 11 & $37,50 \%$ & 0,13 & 0,19 & $\mathrm{x}$ & $\mathrm{x}$ & - & $\mathrm{x}$ & $\mathrm{X}$ \\
\hline PA & 46 & 58 & $26,09 \%$ & 0,07 & 0,08 & 238 & 213 & $-10,50 \%$ & 0,03 & 0,02 \\
\hline AP & 14 & 15 & $7,14 \%$ & 0,18 & 0,2 & $\mathrm{x}$ & 70. & - & $\mathrm{x}$ & 0,06 \\
\hline To & 28 & 26 & $-7,14 \%$ & 0,12 & 0,1 & 84 & 119 & $41,67 \%$ & 0,03 & 0,04 \\
\hline MA & 51 & 50 & $-1,96 \%$ & 0,08 & 0,08 & 183 & 295 & $61,20 \%$ & 0,03 & 0,04 \\
\hline PI & 32 & 35 & $9,38 \%$ & 0,08 & 0,08 & 94 & 180 & $91,49 \%$ & 0,02 & 0,04 \\
\hline $\mathrm{CE}$ & 125 & 143 & $14,40 \%$ & 0,08 & 0,11 & 425 & 612 & $44,00 \%$ & 0,03 & 0,04 \\
\hline RV & 53 & 53 & $0,00 \%$ & 0,1 & 0,1 & 224 & 277 & $23,66 \%$ & 0,04 & 0,04 \\
\hline PB & 46 & 63 & $36,96 \%$ & 0,08 & 0,11 & 168 & 266 & $58,33 \%$ & 0,03 & 0,04 \\
\hline PE & 134 & 155 & $15,67 \%$ & 0,1 & 0,12 & 408 & 501 & $22,79 \%$ & 0,03 & 0,03 \\
\hline AL & 26 & 19 & $-26,92 \%$ & 0,07 & 0,05 & 100 & $\mathrm{x}$ & $=$ & 0,02 & $\mathrm{x}$ \\
\hline SE & 20 & 31 & $55,00 \%$ & 0,07 & 0,11 & 43 & $\mathrm{X}$ & - & 0,01 & $\mathrm{X}$ \\
\hline BA & 211 & 250 & $18,48 \%$ & 0,09 & 0,11 & 737 & 931 & $26,32 \%$ & 0,03 & 0,04 \\
\hline MG & 496 & 570 & $14,92 \%$ & 0,09 & 0,1 & $\mathrm{x}$ & 2670 . & - & $\mathrm{x}$ & 0,05 \\
\hline ES & 109 & 111 & $1,83 \%$ & 0,11 & 0,11 & $\mathrm{X}$ & 324. & - & $\mathrm{X}$ & 0,03 \\
\hline RJ & 1535 & 2283 & $48,73 \%$ & 0,4 & 0,6 & 6538 & 8372 & $28,05 \%$ & 0,14 & 0,18 \\
\hline SP & 5879 & 7240 & $23,15 \%$ & 0,37 & 0,45 & 18173 & 24925 & $37,15 \%$ & 0,12 & 0,15 \\
\hline PR & 424 & 504 & $18,87 \%$ & 0,11 & 0,12 & 1284 & 1640 & $27,73 \%$ & 0,04 & 0,05 \\
\hline SC & 250 & 313 & $25,20 \%$ & 0,09 & 0,11 & $\mathrm{x}$ & 1176 & - & $\mathrm{x}$ & 0,05 \\
\hline RS & 557 & 650 & $16,70 \%$ & 0,12 & 0,15 & $\mathrm{x}$ & 1882 & $=$ & $\mathrm{X}$ & 0,06 \\
\hline MS & 52 & 65 & $25,00 \%$ & 0,09 & 0,1 & 189 & $\mathrm{x}$ & $=$ & 0,04 & $\mathrm{X}$ \\
\hline MIT & 75 & 85 & $13,33 \%$ & 0,1 & 0,1 & 268 & 392 & $46,27 \%$ & 0,04 & 0,05 \\
\hline GO & 134 & 173 & $29,10 \%$ & 0,09 & 0,1 & 481 & 643 & $33,68 \%$ & 0,04 & 0,04 \\
\hline DF & 194 & 205 & $5,67 \%$ & 0,22 & 0,24 & 582 & $\mathrm{x}$ & - & 0,04 & $\mathrm{X}$ \\
\hline
\end{tabular}

Fonte: Elaborado pelo autor com base em dados públicos disponibilizados pelo IBGE - Cadastro Central de Empresas. Nota: Segundo o IBGE, os dados com menos de 3 (três) informantes estão desidentificados com o caractere $X$

O fato dos sistemas produtivos desverticalizados possuírem grande quantidade de unidades empresariais não implica no fim da importância dos grandes conglomerados, os quais assumem a posição 


\section{Gestãoe \\ Desenvolvimento}

de organizadores do sistema produtivo que se articula pela rede de empresas e profissionais envolvidos (CASTELLS, 1999).

Scott (2005), em sua análise sobre Hollywood, identifica as majors (Walt Disney, Warner Bros., Universal, Paramount, 20th Century Fox, Columbia) como as organizadoras do sistema produtivo da indústria do cinema dos Estados Unidos, ao passo que Butcher $(2005 ; 2006)$ identifica a Globo Filmes como elemento crucial da indústria do cinema brasileiro. De fato, ao longo de sua trajetória, a empresa, criada como como departamento da TV Globo em 1997, se consolidou como uma coprodutora decisiva para o sucesso comercial dos filmes nacionais. No quadro 3 abaixo, é possivel visualizar o padrão de concentração do mercado cinematográfico brasileiro nos filmes que contam com a participação da empresa. 
Quadro 3 - Evolução da fatia de produção e da fatia de mercado da Globo Filmes em relação à produção nacional entre os anos de 1998 e 2017

\begin{tabular}{|c|c|c|c|c|}
\hline Ano & $\begin{array}{l}\text { Número de filmes } \\
\text { com participação } \\
\text { da Globo Filmes }\end{array}$ & $\begin{array}{l}\text { Fatia da produção } \\
\text { cinematográfica brasileira } \\
\text { (\%) com participação da } \\
\text { Globo Filmes }\end{array}$ & $\begin{array}{l}\text { Fatia de mercado (\%) } \\
\text { das produções com } \\
\text { participação da Globo } \\
\text { Filmes, segundo público }\end{array}$ & $\begin{array}{l}\text { Fatia de mercado (\%) } \\
\text { das produções com } \\
\text { participação da Globo } \\
\text { Filmes, segundo renda }\end{array}$ \\
\hline 1998 & 1 & $4,35 \%$ & $38,29 \%$ & $32,87 \%$ \\
\hline 1999 & 3 & $10,71 \%$ & $43,42 \%$ & $43,01 \%$ \\
\hline 2000 & 2 & $8,70 \%$ & $42,21 \%$ & $46,38 \%$ \\
\hline 2001 & 3 & $10 \%$ & $54,76 \%$ & $54,33 \%$ \\
\hline 2002 & 2 & $6,90 \%$ & $79,10 \%$ & $77,70 \%$ \\
\hline 2003 & 11 & $36,67 \%$ & $95,16 \%$ & $95,16 \%$ \\
\hline 2004 & 9 & $18,37 \%$ & $77,75 \%$ & $79,32 \%$ \\
\hline 2005 & 7 & $15,22 \%$ & $86,34 \%$ & $85,99 \%$ \\
\hline 2006 & 12 & $16,90 \%$ & $86,35 \%$ & $86,09 \%$ \\
\hline 2007 & 15 & $19,23 \%$ & $55,83 \%$ & $53,72 \%$ \\
\hline 2008 & 13 & $16,46 \%$ & $66,03 \%$ & $64,62 \%$ \\
\hline 2009 & 12 & $14,29 \%$ & $86,60 \%$ & $87,94 \%$ \\
\hline 2010 & 9 & $12 \%$ & $86,78 \%$ & $87,93 \%$ \\
\hline 2011 & 12 & $12,00 \%$ & $74,10 \%$ & $72,05 \%$ \\
\hline 2012 & 13 & $15,66 \%$ & $89,75 \%$ & $89,66 \%$ \\
\hline 2013 & 16 & $12,40 \%$ & $84,99 \%$ & $85,26 \%$ \\
\hline 2014 & 20 & $17,54 \%$ & $74,20 \%$ & $73,96 \%$ \\
\hline 2015 & 18 & $13,53 \%$ & $79,18 \%$ & $80,61 \%$ \\
\hline 2016 & 29 & $20,42 \%$ & $48,47 \%$ & $53,19 \%$ \\
\hline 2017 & 35 & $21,88 \%$ & $45,24 \%$ & $45,22 \%$ \\
\hline
\end{tabular}

Fonte: Elaborado pelo autor com base em dados públicos disponibilizados pela ANCINE (2018) e filmografia informada no site da Globo Filmes 
Pelo quadro acima, podemos verificar que 2003 é o ano em que a Globo Filmes consolida o seu modelo de negócio e se envolve com um número crescente de produções cinematográficas brasileiras, conquistando sempre elevadas fatias de mercado. 0 ano de 2016 é a exceção ao padrão de concentração mencionado, fato que decorre da entrada da Rede Record de Televisão no mercado cinematográfico, através da adaptação de uma de suas novelas para o cinema, a qual se tornou o filme com a maior venda de ingressos da história do cinema brasileiro. Sem dúvidas, a entrada desse grupo no mercado cinematográfico carrega consigo a possibilidade de alterar o padrão competitivo do setor. Todavia, ainda é cedo para apontarmos conclusões mais precisas, uma vez que em 2017 a Rede Record de Televisão não lançou nenhum filme nos cinemas brasileiros, mas o fez em 2018 com elevado sucesso comercial outra vez. Como até o momento de fechamento deste artigo os dados consolidados pela ANCINE se estendem até 2017, restringiremos a nossa análise a tal ano.

De toda forma, concordamos com Butcher $(2005 ; 2006)$ que sugere uma definição do real sentido de se fazer cinema independente no Brasil como sendo aquela produção que não conta com a participação da Globo Filmes. Entretanto, além da Globo Filmes, que atua de maneira decisiva na coprodução dos filmes, não podemos desconsiderar a força econômica das majors, as quais, por serem as principais distribuidoras de conteúdo audiovisual do Mundo, também devem ser consideradas como elemento importante na organização da indústria do cinema brasileiro.

Se, ao falarmos da Globo Filmes, fizemos a ressalva da entrada recente da Rede Record de Televisão no mercado cinematográfico brasileiro, ao tratarmos da importância das majors na organização da indústria do cinema nacional também precisamos estabelecer algumas considerações. Segundo dados disponibilizados pela ANCINE no relatório "Informe Anual Distribuição em Salas 2016", as distribuidoras denominadas como majors respondem por mais de 75\% dos ingressos de cinema vendidos no Brasil, porém quando analisa-se apenas as produções nacionais, a participação dessas distribuidoras cai significativamente. De fato, ocorreu uma importante mudança na distribuição do cinema nacional, que desde 2010 passou a ser realizado principalmente por empresas nacionais.

Apesar da recente entrada da Rede Record de Televisão na produção cinematográfica brasileira e da participação crescente das distribuidoras nacionais na distribuição do conteúdo brasileiro, ainda reconhecemos que a Globo Filmes juntamente com as majors se configuram nos nós centrais na organização do sistema produtivo. A primeira, por ser parte do maior grupo midiático nacional, atua de maneira decisiva no marketing e na promoção do filme, assim como no desenvolvimento do projeto (roteiro, elenco e padrão de filmagem) e, além disso, não podemos deixar de considerar a influência do padrão audiovisual da sua teledramaturgia sobre a cinematografia (BUTCHER, 2005). As majors, por sua vez, são responsáveis pela estratégia de distribuição dos filmes, etapa crucial para a performance 
comercial das produções cinematográficas e na qual assumem uma condição singular de liderança, além disso, essas empresas também respondem pelo financiamento de algumas produções, sendo esta última função decorrente do Artigo $3^{\circ}$ da Lei do Audiovisual.

Embora a Globo Filmes e as majors sejam elementos centrais na organização do sistema produtivo, as produtoras são as responsáveis pela execução dos projetos (sejam os de grande apelo comercial ou os mais autorais), pelos processos de aprendizagem e de inovação, bem como pela oferta de variados projetos que serão realizados em parceria com as majors, com a Globo Filmes ou sem a participação delas.

Dentro do sistema produtivo, as produtoras e as demais empresas envolvidas interagem na medida em que o projeto avança pelas fases de produção, mobilizando trabalhadores com as mais diversas habilidades e competências. Entretanto, há diferentes padrões de interação que decorrem das diferentes propostas cinematográficas e dos distintos níveis de competitividade dos filmes no mercado, de modo que podemos reconhecer um subsistema hegemônico organizado pela Globo Filmes e pelas majors e outro independente, cujos projetos estão descolados desses dois elementos.

Ao propormos essa interpretação, nos afastamos da definição estabelecida na Lei do Audiovisual (BRASIL, 1993), posteriormente atualizada pela Medida Provisória 2.228-1 de 2001, que define a produção independente como aquela "cuja empresa produtora, detentora majoritária dos direitos patrimoniais sobre a obra, não tenha qualquer associação ou vínculo, direto ou indireto, com empresas de serviços de radiodifusão de sons e imagens ou operadoras de comunicação eletrônica de massa por assinatura" (BRASIL, 2001). Não se trata de uma crítica à definição da Lei, porém esta não atende aos interesses da presente pesquisa, assim, recorreremos ao risco de estabelecermos um critério próprio, segundo o qual a produção independente se define pela ausência da Globo Filmes e das majors no projeto, ao passo que quando uma dessas empresas participar do projeto, este será considerado integrante do subsistema hegemônico. Como já mencionado, em 2016, a Rede Record de Televisão entrou no mercado cinematográfico, de modo que se configurou um fato novo na organização do sistema produtivo do cinema brasileiro, de maneira que as produções realizadas pela empresa devem ser classificadas como hegemônicas em função do alcance comercial que possui. Entretanto, ainda precisamos de mais tempo para avaliar a estratégia da empresa e os seus impactos na organização do sistema produtivo da indústria cinematográfica brasileira.

Em suma, é fundamental que se entenda aqui que a nossa interpretação sobre a dinâmica produtiva da indústria do cinema no Brasil não reside na empresa (produtora de filmes), mas nas interações estabelecidas entre as empresas na consecução de seus projetos, o que se justifica pela desverticalização do sistema produtivo. Nesse sentido, a definição de "independente", neste artigo, decorre das parcerias envolvidas na execução do projeto e não pela ausência de vínculo do produtor majoritário com as empresas 


\section{Gestãoe \\ Desenvolvimento}

concessionárias de serviços de radiodifusão e cabodifusão. Isso implica que um mesmo produtor pode realizar um projeto independente e em outro momento um projeto hegemônico, ou até mesmo possuir dois projetos em curso ao mesmo tempo, sendo um independente e outro hegemônico. Naturalmente, qualquer tipologia é passível de críticas, uma vez que dificilmente conseguirá abarcar com sucesso todos os casos analisados. Porém, acreditamos que a nossa opção funcionará em sua maioria para o nosso propósito.

De acordo com nosso critério, podemos verificar, no quadro 4, que a maior parte da produção cinematográfica brasileira pertence ao subsistema independente, porém, como já evidenciamos anteriormente (ver quadro 3), a concentração do mercado está no subsistema hegemônico. 


\section{Gestãoe \\ Desenvolvimento}

e-ISSN: 2446-6875

p-ISSN: 1807-5436

Quadro 4 - Evolução da produção cinematográfica nos subsistemas hegemônico e independente da indústria cinematográfica brasileira entre os anos de 2003 e 2017

\begin{tabular}{|c|c|c|c|c|c|c|c|c|c|c|c|c|c|c|c|}
\hline Ano & 2003 & 2004 & 2005 & 2006 & 2007 & 2008 & 2009 & 2010 & 2011 & 2012 & 2013 & 2014 & 2015 & 2016 & 2017 \\
\hline $\begin{array}{l}\text { Filmes } \\
\text { coproduzidos } \\
\text { pela Globo } \\
\text { Filmes } \\
\text { distribuídos } \\
\text { por uma das } \\
\text { Majors }\end{array}$ & 10 & 7 & 7 & 9 & 10 & 9 & 5 & 6 & 5 & 3 & 4 & 2 & 3 & 3 & 3 \\
\hline $\begin{array}{l}\text { Filmes } \\
\text { coproduzidos } \\
\text { pela Globo } \\
\text { Filmes sem } \\
\text { distribuição } \\
\text { de uma das } \\
\text { Majors }\end{array}$ & 1 & 2 & 0 & 3 & 5 & 4 & 7 & 3 & 7 & 10 & 12 & 18 & 15 & 26 & 32 \\
\hline $\begin{array}{l}\text { Filmes sem } \\
\text { participação da } \\
\text { Globo Filmes } \\
\text { e distribuído } \\
\text { por uma das } \\
\text { Majors }\end{array}$ & 5 & 9 & 6 & 7 & 5 & 6 & 7 & 7 & 5 & 5 & 4 & 5 & 3 & 2 & 5 \\
\hline $\begin{array}{l}\text { Filmes sem } \\
\text { participação } \\
\text { da Globo } \\
\text { Filmes e sem } \\
\text { distribuição } \\
\text { de uma das } \\
\text { Majors - } \\
\text { Plenamente } \\
\text { independente }\end{array}$ & 13 & 31 & 33 & 52 & 58 & 60 & 65 & 58 & 83 & 65 & 109 & 89 & 112 & 110 & 120 \\
\hline $\begin{array}{l}\text { Filmes } \\
\text { realizados pela } \\
\text { Rede Record } \\
\text { de Televisão }\end{array}$ & - & - & - & - & - & - & - & - & - & - & - & - & - & 1 & - \\
\hline
\end{tabular}

Fonte: Elaborado pelo autor com base em dados públicos disponibilizados pela ANCINE (2018) e filmografia informada no site da Globo Filmes 
No quadro 5 desagregamos os dados do quadro 4, apresentado anteriormente, por sede da produtora, de maneira que podemos compreender melhor a dinâmica produtiva dos centros de produção que integram o sistema produtivo da indústria do cinema brasileiro.

Quadro 5 - Produção cinematográfica nos subsistemas hegemônico e independente da indústria cinematogrăfica brasileira entre os anos de 2003 e 2007, por sede da produtora

\begin{tabular}{|c|c|c|c|c|c|c|}
\hline Ano & UF & $\begin{array}{l}\text { Filmes } \\
\text { coproduzidos } \\
\text { pela Globo } \\
\text { Filmes } \\
\text { distribuídos por } \\
\text { uma das Majors }\end{array}$ & $\begin{array}{l}\text { Filmes } \\
\text { coproduzidos } \\
\text { pela Globo } \\
\text { Filmes sem } \\
\text { distribuição } \\
\text { de uma das } \\
\text { Majors } \\
\end{array}$ & $\begin{array}{l}\text { Filmes sem } \\
\text { participação da } \\
\text { Globo Filmes e } \\
\text { distribuído por } \\
\text { uma das Majors }\end{array}$ & $\begin{array}{l}\text { Filmes sem participação } \\
\text { da Globo Filmes e sem } \\
\text { distribuição de uma das } \\
\text { Majors - Plenamente } \\
\text { independente }\end{array}$ & $\begin{array}{l}\text { Filmes } \\
\text { realizados } \\
\text { pela Rede } \\
\text { Record de } \\
\text { Televisão }\end{array}$ \\
\hline \multirow{3}{*}{2003} & $\mathrm{RJ}$ & 7 & 1 & 2 & 11 & - \\
\hline & $\mathrm{SP}$ & 2 & - & 3 & 2 & - \\
\hline & Outros & 1 & - & - & - & - \\
\hline \multirow{3}{*}{2004} & $\mathrm{RJ}$ & 5 & 1 & 5 & 18 & - \\
\hline & $\mathrm{SP}$ & 1 & 1 & 4 & 9 & - \\
\hline & Outros & 1 & - & - & 4 & - \\
\hline \multirow{3}{*}{2005} & RJ & 7 & - & 3 & 17 & - \\
\hline & $\mathrm{SP}$ & - & - & 2 & 8 & - \\
\hline & Outros & - & - & 1 & 8 & - \\
\hline \multirow{3}{*}{2006} & RJ & 8 & 3 & 6 & 26 & - \\
\hline & SP & 1 & - & 1 & 15 & - \\
\hline & Outros & - & - & - & 11 & - \\
\hline \multirow{3}{*}{2007} & RJ & 7 & 4 & 3 & 29 & - \\
\hline & SP & 2 & 1 & 2 & 19 & - \\
\hline & Outros & 1 & - & - & 10 & - \\
\hline \multirow{3}{*}{2008} & RJ & 7 & 2 & 3 & 28 & - \\
\hline & SP & 2 & 2 & 2 & 21 & - \\
\hline & Outros & - & - & 1 & 11 & - \\
\hline \multirow{3}{*}{2009} & RJ & 5 & 7 & 2 & 32 & - \\
\hline & SP & - & - & 5 & 21 & - \\
\hline & Outros & - & - & - & 12 & - \\
\hline
\end{tabular}




\begin{tabular}{|c|c|c|c|c|c|c|}
\hline \multirow{3}{*}{2010} & RJ & 6 & 2 & 2 & 22 & - \\
\hline & SP & - & 1 & 5 & 20 & - \\
\hline & Outros & - & - & - & 16 & - \\
\hline \multirow{3}{*}{2011} & $\mathrm{RJ}$ & 4 & 5 & 1 & 33 & - \\
\hline & SP & 1 & 2 & 4 & 27 & - \\
\hline & Outros & - & - & - & 23 & - \\
\hline \multirow{3}{*}{2012} & RJ & 2 & 8 & 2 & 21 & - \\
\hline & $\mathrm{SP}$ & 1 & 2 & 3 & 27 & - \\
\hline & Outros & - & - & - & 17 & - \\
\hline \multirow{3}{*}{2013} & $\mathrm{RJ}$ & 2 & 8 & 3 & 35 & - \\
\hline & $\mathrm{SP}$ & 2 & 4 & 1 & 38 & - \\
\hline & Outros & - & - & - & 36 & - \\
\hline \multirow{3}{*}{2014} & $\mathrm{RJ}$ & 2 & 12 & 2 & 25 & - \\
\hline & $\mathrm{SP}$ & - & 6 & 3 & 42 & - \\
\hline & Outros & - & - & - & 22 & - \\
\hline \multirow{3}{*}{2015} & RJ & 3 & 11 & 1 & 48 & - \\
\hline & SP & - & 3 & 2 & 40 & - \\
\hline & Outros & - & 1 & - & 24 & - \\
\hline \multirow{3}{*}{2016} & RJ & 1 & 11 & - & 37 & - \\
\hline & SP & 2 & 11 & 2 & 46 & 1 \\
\hline & Outros & - & 4 & - & 27 & - \\
\hline \multirow{3}{*}{2017} & RJ & 3 & 19 & 1 & 46 & - \\
\hline & $\mathrm{SP}$ & - & 11 & 4 & 40 & - \\
\hline & Outros & - & 2 & - & 34 & - \\
\hline
\end{tabular}

Fonte: Elaborado pelo autor com base em dados públicos disponibilizados pela ANCINE (2018) e filmografia informada no site da Globo Filmes

Nos gráficos 7, 8 e 9, apresentamos os mesmos dados do quadro 5 para faciltar a visualização das informações. Podemos perceber claramente que apesar de haver uma dispersão da produção cinematográfica brasileira para outros centros de produção, além do eixo Rio-São Paulo, especialmente Minas Gerais, Pernambuco, Distrito Federal e Paraná, os quais apresentam perenidade na produção desde 2008, e Rio Grande do Sul, que já possui perenidade produtiva desde 2000, estes desenvolveram, no período selecionado, poucos projetos inseridos no subsistema hegemônico, destacando-se que no período 
2009-2014 nenhum projeto hegemônico foi realizado fora do eixo Rio-SP. Evidentemente isso limita o alcance comercial dos projetos, porém, importante sublinhar, não impede a dinâmica de aprendizagem mencionada anteriormente, que é parte fundamental do processo de desenvolvimento dos centros de produção.

Gráfico 7 - Produção cinematográfica nos subsistemas hegemônico e independente da indústria cinematográfica brasileira entre os anos de 2003 e 2007, por sede da produtora

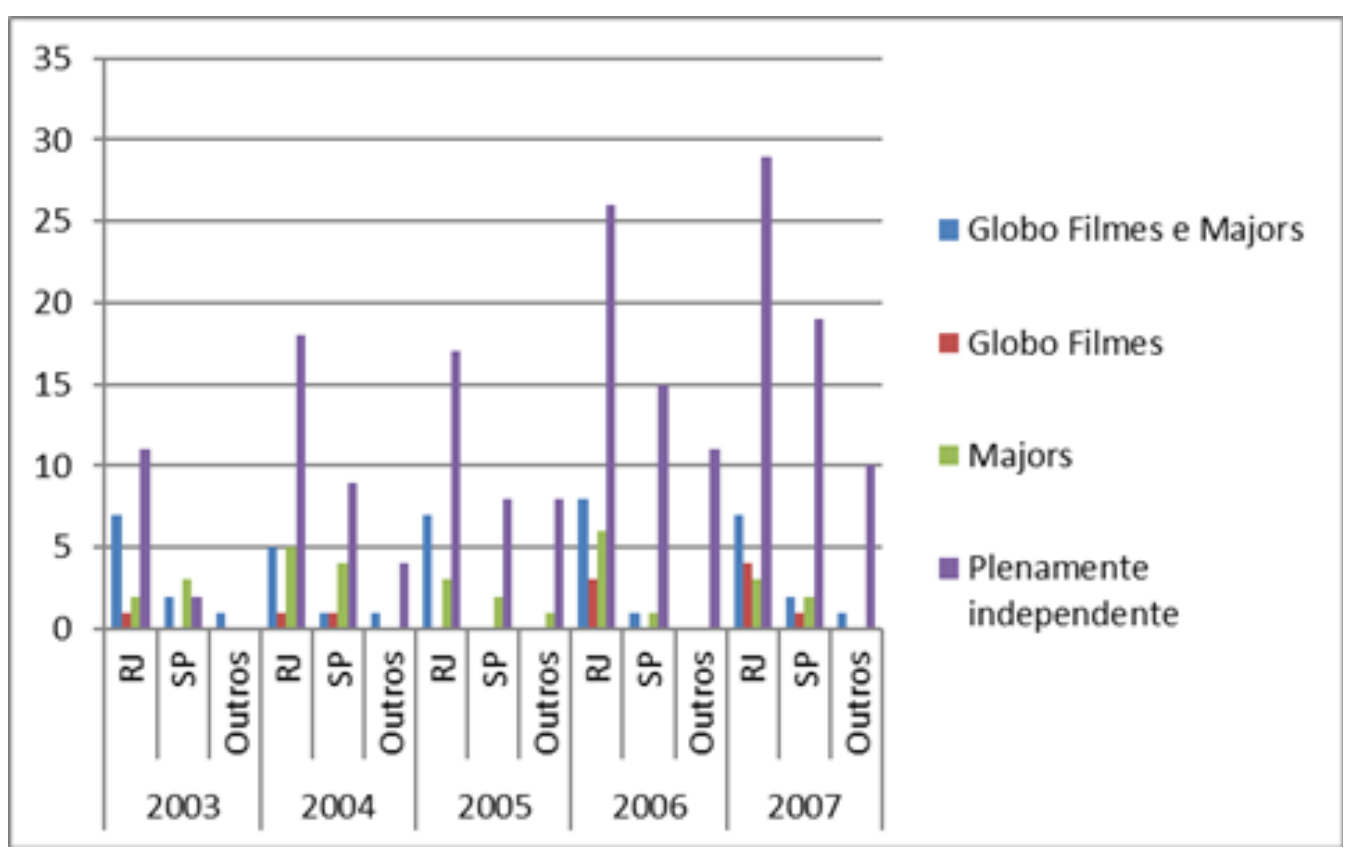

Fonte: Elaborado pelo autor com base em dados públicos disponibilizados pela ANCINE (2018) e filmografia informada no site da Globo Filmes 
Gráfico 8 - Produção cinematográfica nos subsistemas hegemônico e independente da indústria cinematográfica brasileira entre os anos de 2008 e 2012, por sede da produtora

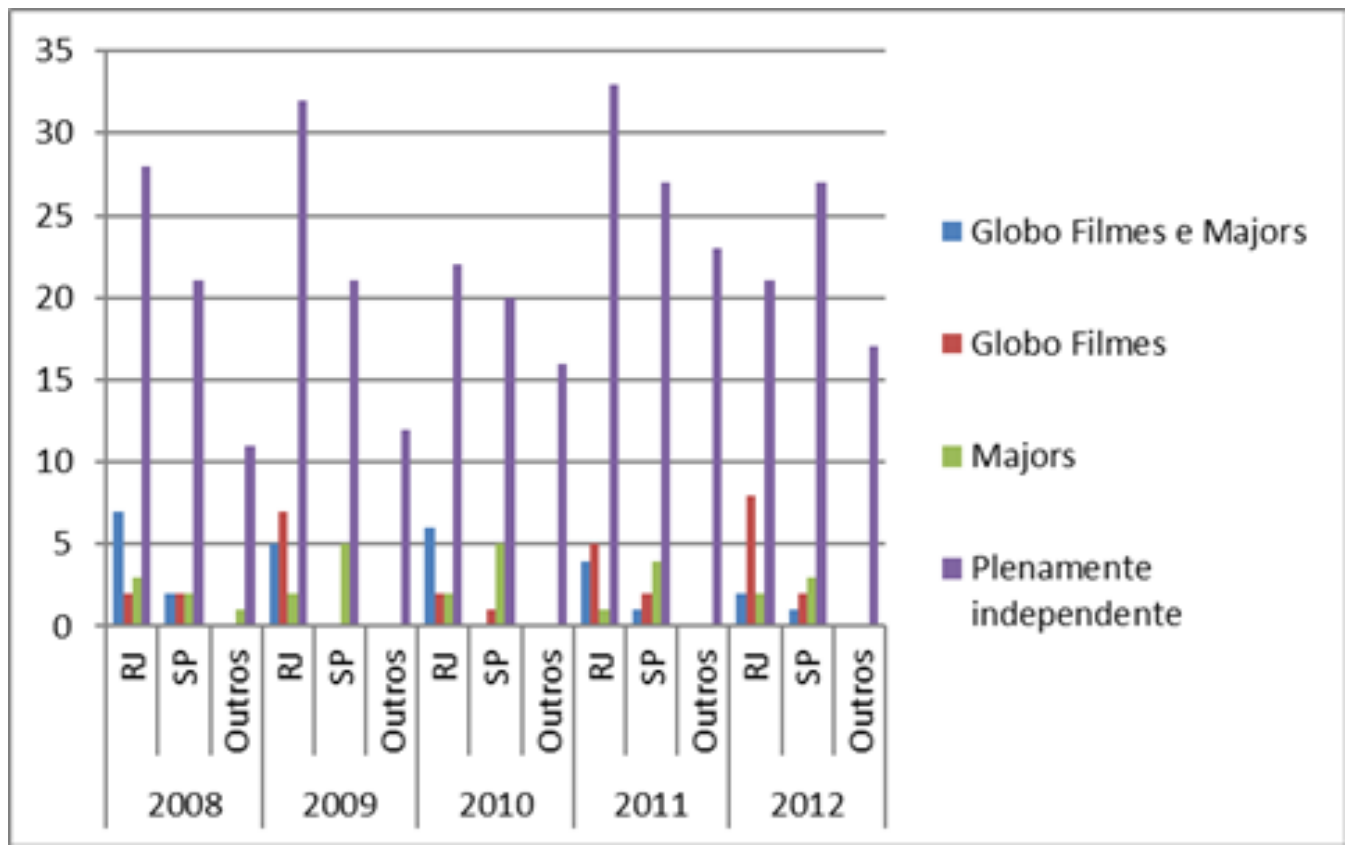

Fonte: Elaborado pelo autor com base em dados públicos disponibilizados pela ANCINE (2018) e filmografia informada no site da Globo Filmes 
Gráfico 9 - Produção cinematográfica nos subsistemas hegemônico e independente da indústria cinematográfica brasileira entre os anos de 2013 e 2017, por sede da produtora

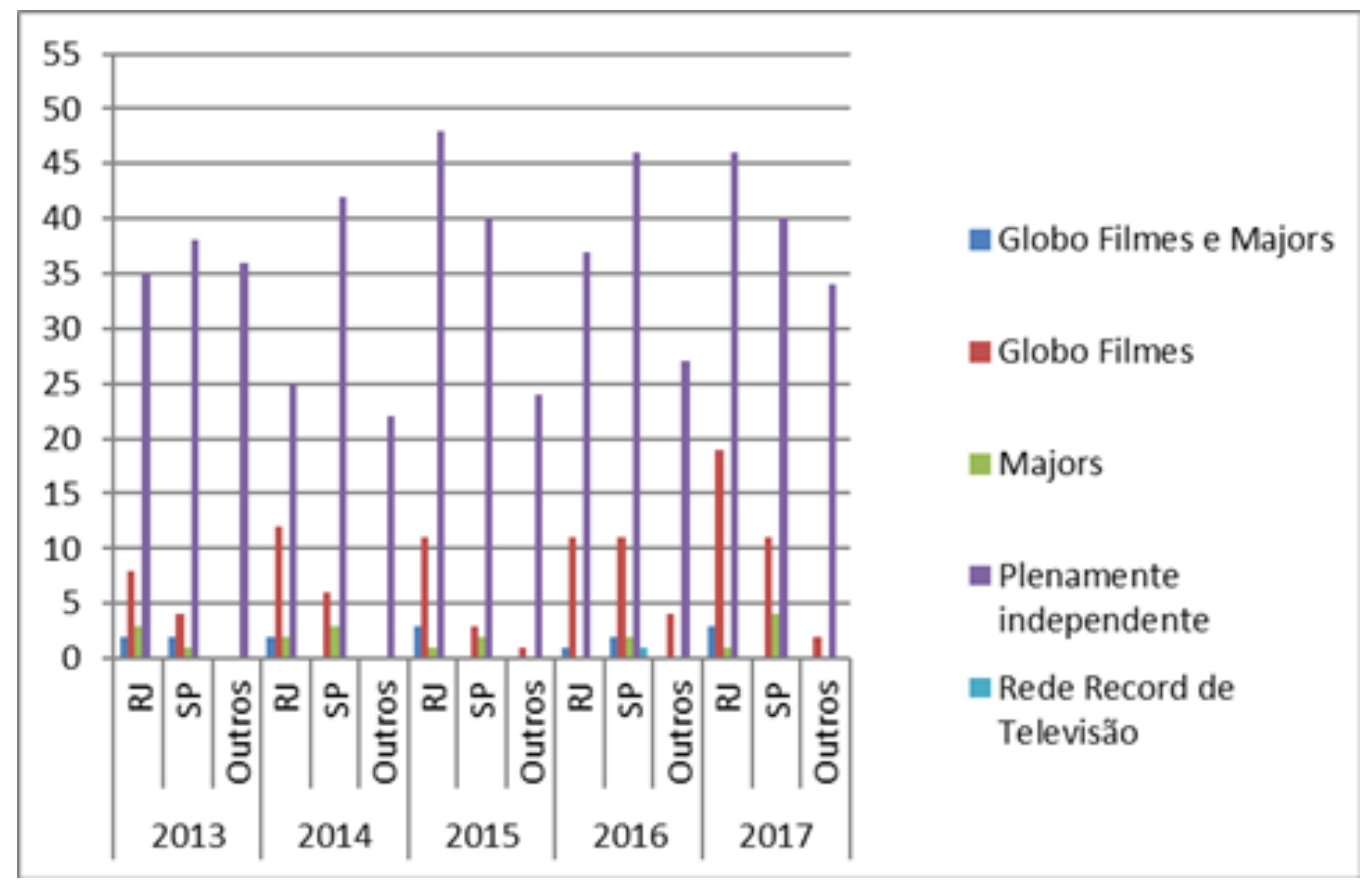

Fonte: Elaborado pelo autor com base em dados públicos disponibilizados pela ANCINE (2018) e filmografia informada no site da Globo Filmes

Vale mencionar que dos poucos projetos hegemônicos desenvolvidos pelos centros de produção emergentes, a maioria foi realizada por produtoras do Rio Grande do Sul, que responderam por uma produção desse tipo em 2003, 2004, 2005, 2007, 2015, 2016 e 2017; enquanto que as produtoras do Ceará realizaram um filme em 2008 e outro em 2016; e nesse último ano também tivemos uma produção hegemônica de Pernambuco e do Distrito Federal. Assim, notamos uma importante diferença entre os centros de produção emergentes, uma vez que, além da conquista da perenidade produtiva há mais tempo, o Rio Grande do Sul possui produtoras com maior capacidade de desenvolvimento de projetos hegemônicos. Em outras palavras, dos centros emergentes de produção, as produtoras do Rio Grande do Sul são as que mais conseguem estabelecer conexões produtivas com as empresas responsáveis pela organização do sistema produtivo da indústria do cinema no Brasil. 
Nos centros de produção consolidados do Rio de Janeiro e de São Paulo, verificamos, além do notável crescimento da participação dos projetos independentes no total de filmes realizados, a permanente realização de projetos classificados como integrantes do subsistema hegemônico, de maneira que se evidencia a estratégia de algumas produtoras que ora se engajam em projetos hegemônicos, ora em projetos independentes.

O trânsito de uma mesma produtora, através de seus variados projetos, entre os subsistemas pode ser compreendido como parte de sua estratégia competitiva, através da qual o portfólio da produtora permite a sua inserção nos fluxos de inovação e de aprendizagem (muito presentes nos projetos do subsistema independente) ao mesmo tempo em que viabiliza a geração de bons resultados comerciais (mais presentes no subsistema hegemônico). Além disso, permite à produtora gerir sua reputação, uma vez que nos mercados culturais e criativos é comum se "exigir" comprometimento das produtoras com a geração de valor cultural através de seus projetos, de maneira que, se uma produtora se dedicar apenas à realização de projetos essencialmente comerciais, ela tende a perder reputação frente aos seus pares.

Como o argumento central deste artigo está na análise da indústria do cinema como um sistema produtivo, desejamos enfatizar a interdependência entre a produção de filmes hegemônicos com os identificados como independentes. Desse modo, a intenção foi demonstrar a importância da coexistência de projetos hegemônicos com outros independentes dentro de um mesmo sistema produtivo, permitindo que o sistema se reproduza no curto prazo a partir da circulação financeira gerada pelos primeiros e que seja sustentável no longo prazo através da renovação dos talentos e das linguagens através dos projetos independentes. Por essa ótica de análise, podemos identificar uma dinâmica de competição e de cooperação entre os variados projetos desenvolvidos no país, uma vez que competem por recursos, mas cooperam para a reprodução do sistema produtivo. Benhamou (2007) define esse processo como uma dialética da inovação e da padronização, que se reflete "no caráter dicotômico das estruturas da oferta, onde coexistem pequenas unidades e grupos que mantêm relações ao mesmo tempo conflitantes e complementares" (BENHAMOU, 2007, p. 118).

Ao analisarmos os dados apresentados anteriormente, fica evidente que está em desenvolvimento no Brasil um sistema produtivo da indústria do cinema, pois em seu conjunto existem projetos hegemônicos e independentes, liderados por produtoras que geram uma rede de interações entre si e demais agentes produtivos em uma dinâmica de competição e de cooperação ao mesmo tempo. Mas, além disso, interessa-nos investigar como o fortalecimento da produção nacional se relaciona com a emergência dos novos centros de produção no país.

Nesse sentido, ao analisarmos o período de 1995 a 2017, percebemos a expansão do sistema produtivo da indústria do cinema no Brasil, levando à emergência de novos centros de produção no 
Brasil, especialmente a partir do ano 2008. Porém estes ainda não conseguiram internalizar em seus complexos produtivos locais uma dinâmica produtiva consistente de geração de projetos classificáveis como hegemônicos.

Diante disso, entendemos que apenas os centros de produção do Rio de Janeiro e de São Paulo estão consolidados, ao passo que os demais centros emergentes, apesar do aumento da produção verificado a partir de 2008, ainda se inserem no sistema produtivo nacional como fontes de aprendizagem, de inovação e de incubação de novos talentos que em algum momento da carreira tendem a migrar para os centros de produção consolidados.

\section{CONSIDERAÇÕES FINAIS}

Conforme enfatizado no início do trabalho, o objetivo deste artigo era evidenciar o fortalecimento da produção nacional e a emergência de novos centros de produção no país a partir da sua análise como um sistema produtivo. Nesse sentido, a análise da dinâmica produtiva da indústria do cinema no Brasil e a emergência de novos centros de produção foram tratadas pelo olhar do conjunto produtivo, evitando a análise centrada em empresas ou em projetos específicos.

Nesse percurso, reconhecemos que a indústria do cinema possui um sistema produtivo bastante desverticalizado e intensivo em interações produtivas entre as empresas envolvidas, de maneira que o resultado espacial desse processo é a concentração da produção nas cidades que ocupam o topo da hierarquia urbana. Formam-se, nessas cidades, aglomerações produtivas de empresas e de trabalhadores, cuja proximidade permite alcançar as vantagens do mercado de trabalho concentrado e a inserção nos fluxos de informação e de inovação.

Os dados apresentados ao longo do trabalho confirmam o fortalecimento da produção cinematográfica no Brasil, a qual possui um padrão espacial extremamente concentrado nos centros de produção do Rio de Janeiro e de São Paulo, embora, a partir de 2008, seja possível evidenciar a emergência de novos centros de produção no país, especialmente nos estados do Rio Grande do Sul, Minas Gerais, Pernambuco, Paraná e Distrito Federal. Chamamos esse processo de "dispersão concentrada" da produção cinematográfica nacional, pois apesar do aumento do número de cidades no Brasil com alguma dinâmica produtiva perene desde 2008, a dispersão se manifesta de maneira extremamente seletiva em termos espaciais, engendrando a gênese de um reduzido número de novos centros de produção.

Em outras palavras, reconhecer a existência de um processo de dispersão da dinâmica produtiva da indústria do cinema no Brasil não significa apontar para um processo amplo de dispersão das atividades produtivas cinematográficas. A tendência é a formação de novos centros de produção com diferentes 
tamanhos e força de mercado, mas que ainda dependem de estarem localizados em determinadas cidades. Todavia se, por um lado, os dados confirmaram o surgimento de novos centros de produção no país, por outro lado, mostraram que estes ainda estão longe de obterem performance consistente de mercado.

De acordo com a nossa lente de análise, interpretamos o sistema produtivo da indústria do cinema em dois subsistemas complementares, um hegemônico e outro independente e, nesse sentido, evidenciamos que os novos centros de produção se desenvolvem principalmente pela execução de projetos independentes, limitando sobremaneira o resultado comercial dos seus filmes.

Embora a realização de filmes classificados como parte do subsistema independente seja fundamental para a sustentabilidade da indústria no longo prazo, em função da geração de fluxos de aprendizagem e de inovação, tais projetos, em geral, possuem reduzido alcance comercial e por isso não são capazes de sustentar o desenvolvimento do centro de produção. Por outro lado, a realização de filmes classificados como integrantes do subsistema hegemônico geram importantes resultados comerciais no curto prazo, mas restringem a renovação do sistema em termos de novos talentos e de linguagens, em função da aversão que possuem ao risco. Assim, para que o sistema se reproduza no curto prazo e se renove no longo prazo é fundamental a relação de complementaridade entre os projetos hegemônicos e os independentes.

Por esse aspecto, no período em análise neste artigo, que compreende os anos de 1995 até 2017, podemos identificar apenas dois centros de produção consolidados no país, Rio de Janeiro e São Paulo, que são os únicos que possuem perenidade na realização de projetos inseridos nos dois subsistemas. Os demais centros emergentes, por sua vez, ainda possuem o desafio de desenvolver a capacidade de realizar projetos possiveis de serem classificados como hegemônicos ou tenderão a perder seus principais talentos para os centros do Rio e de São Paulo.

Assim, embora não haja nenhuma garantia, é possível que alguns dos novos centros de produção no Brasil consigam capturar alguma fatia de mercado mais expressiva em um futuro próximo, desde que consigam internalizar a complementaridade entre os subsistemas hegemônico e independente. Por ora, a boa notícia é a evidência clara de uma dinâmica produtiva que emerge para além dos centros consolidados de Rio e São Paulo. 


\section{REFERÊNCIAS}

ALBERSE, A. Blockbusters. Rio de Janeiro: Elsevier, 2014.

ANCINE. Informe Anual Distribuição em Salas 2016. Disponível em: https://oca.ancine.gov.br/sites/ default/files/repositorio/pdf/informe_distribuicaodetalhado_2016.pdf. Acesso em 22 de março de dezembro de 2018.

ANCINE. Listagem de filmes brasileiros lançados 1995 a 2017. Disponivel em: https://oca.ancine.gov. br/sites/default/files/repositorio/pdf/2102.pdf. Acesso em 15 de dezembro de 2018.

BENHAMOU, F. A economia da cultura. Cotia: Ateliê Editorial, 2007.

BRASIL. Lei № 8.685, de 20 de Julho de 1993. Cria mecanismos de fomento à atividade audiovisual e dá outras providências. Brasilia, DF, 1993. Disponível em: http://www.planalto.gov.br/ccivil_03/leis/l8685. htm. Acesso em 15 de abril de 2018.

BRASIL. Medida Provisória N² 2.228-1, de 06 de Setembro de 2001. Estabelece princípios gerais da Política Nacional do Cinema, cria o Conselho Superior do Cinema e a Agência Nacional do Cinema - ANCINE, institui o Programa de Apoio ao Desenvolvimento do Cinema Nacional - PRODECINE, autoriza a criação de Fundos de Financiamento da Indústria Cinematográfica Nacional - FUNCINES, altera a legislação sobre a Contribuição para o Desenvolvimento da Indústria Cinematográfica Nacional e dá outras providências. Brasilia, DF, 2001. Disponivel em: http://www.planalto.gov.br/ccivil_03/mpv/2228-1.htm. Acesso em 15 de abril de 2018.

BUTCHER, P. A dona da história: origens da Globo Filmes e seu impacto no audiovisual brasileiro. Dissertação de mestrado apresentada ao Programa de Pós-Graduação em Comunicação e Cultura da Escola de Comunicação da Universidade Federal do Rio de Janeiro, 2006.

BUTCHER, P. Cinema brasileiro hoje. São Paulo: Publifolha, 2005.

CASTELLS, M. A sociedade em rede: a era da informação: economia, sociedade e cultura; volume 1. São Paulo: Paz e Terra, 1999.

DINIZ, C. C. e LEMOS, M. B. (orgs.). Economia e território. Belo Horizonte: UFMG, 2005.

LIPOVETSKY, G. e SERROY, J. A estetização do mundo: viver na era do capitalismo artista. São Paulo: Companhia das Letras, 2015.

SCOTT, A. J. The cultural economy of cities. Londres: Sage, 2000. 
SCOTT, A. J. On Hollywood: the place, the industry. Nova Jersey: Priceton University Press, 2005.

STORPER, M. e CHRISTOPHERSON, S. Flexible specialization and regional industrial agglomerations: the case of the U. S. motion-picture industry. IN: Annals of the American Geographers, 77, 1997. p. 260-82.

STORPER, M. Keys to the city: how economics, institutions, social interactions, and politics shape development. New Jersey: Princeton University Press, 2013.

STORPER, M. The regional world: territorial development in a global economy. New York: Guilford, 1997.

VELTZ, P. Mundialización, ciudades y territorios: la economía de archipiélago. Barcelona: Ariel, 1999. 